\title{
Scoring systems for upper gastrointestinal bleeding: Which one scores better?
}

\author{
Vinay Dhir ${ }^{1} \cdot$ Rahul Shah $^{1}$ \\ Published online: 12 March 2019 \\ (C) Indian Society of Gastroenterology 2019
}

Scoring systems allow us to compartmentalize the myriad presentations, risk factors, and outcomes, into more or less uniform groups, so as to prioritize management and resource allocation. Multiple scoring systems abound in gastroenterology, often several for the same disorder. Their routine utilization in bedside management depends upon many factors, ease and practicality of use being the major one. While some like acute physiology and chronic health evaluation (APACHE), and model for endstage liver disease (MELD) became rapidly integrated in clinical management, others are not routinely utilized despite strong recommendations from several societies and organizations. Scoring systems for upper gastrointestinal bleed (UGIB) fall into the latter category. A recent survey in the USA revealed that, of the 1402 emergency physicians, internists, and gastroenterologists surveyed, only $53 \%$ had ever heard of these, and $30 \%$ had ever used any scoring system [1]. While this is not an indictment of the scoring systems, it does convey the problem of crossspecialty awareness, and difficulty in remembering and recalling the parameters during an emergency.

UGIB presents in different age groups and has multiple etiologies, variceal, and non-variceal being the main categorization. Elderly patients often have co-morbidities, which influence the outcome. An ideal scoring system should take these differences into account, should be simple and easy to use, and should answer important prognostic questions like need for admission, need for intensive care and blood transfusion, need and timing of index endoscopy, possible course, and hospitalization; and likely outcome.

Scoring systems for UGIB were developed and validated from 1990s onwards [2-9]. The primary aim was to segregate the patients into low-risk and high-risk groups. The scoring

Vinay Dhir

vinaydhir@gmail.com

1 Institute of Digestive and Liver Care, S L Raheja Hospital, Mahim (W), Mumbai 400 016, India systems were developed with differing goals like assessing mortality, or interventions, or blood transfusions, and we should remember this while comparing them. Some of these required only clinical data, while others needed additional endoscopic findings (Table 1). The Glasgow Blatchford score (GBS) [2] was developed with the aim of predicting the risk of re-interventions like endoscopy or surgery. It is a preendoscopy clinical score ranging from 0 to 23 . Patients with a score of $0-1$ do not require early endoscopy or hospital admission. The Rockall score [4] has both clinical and endoscopic components, and can also be used solely as a clinical score before endoscopy. However, it remains the most widely used post-endoscopic risk assessment score. Each of the five components of the Rockall score (age, shock, co-morbidity, endoscopic diagnosis, and evidence of bleeding) is an independent prognostic factor. The AIMS65 (albumin, international normalized ratio [INR], mental status, systolic blood pressure, age $>65$ years) score [3] also has five elements, but it is a pre-endoscopy score, easy to remember and calculate at the bedside. It predicts length of hospital stay and mortality. Several other scores have also been described with differing goals. It has also been proposed that the use of a single criterion, increasing blood urea nitrogen at $24 \mathrm{~h}$, may predict a worse outcome in patients with non-variceal UGIB [10].

Multiple large prospective studies have proved the utility of these scores in predicting the need for interventions, prolonged hospitalization, and mortality [11-13]. It was also possible to segregate a group of patients who were at low risk and did not need hospital admission. Several gastroenterology and endoscopy societies have recommended and encouraged the utilization of these scoring systems in patient management.

In this issue of the Journal, Chandnani et al. [14] prospectively assessed UGIB scoring systems in 300 patients in western India followed up for 30 days. Variceal bleed was the commonest cause, and the patient population was younger. The mortality rate was $10 \%$, while $16.6 \%$ patients had re-bleeding. Their results were in tune with the findings of the other published studies. The Rockall score was superior in predicting mortality, while 
Table 1 Scoring systems for upper gastrointestinal bleeding

\begin{tabular}{lll}
\hline Primary outcome & Clinical scores & Endoscopy scores \\
\hline Time to endoscopy & & $\begin{array}{l}\text { T score } \\
\text { Re-bleeding }\end{array}$ \\
& & $\begin{array}{l}\text { Forrest } \\
\text { BBS }\end{array}$ \\
Need for re-intervention & GBS & \\
Length of stay & AIMS65 & CSMCPI \\
Mortality & Rockall & Rockall \\
& AIMS65 & PNED \\
\hline
\end{tabular}

$B B S$ Baylor bleeding score, GBS Glasgow Blatchford score, CSMCPI Cedars-Sinai medical centre predictive index, $P N E D$ Progetto Nazionale Emorragia Digestiva, AIMS65 albumin, international normalized ratio (INR), mental status, systolic blood pressure, age $>65$

Progetto Nazionale Emorragia Digestiva (PNED) was better for predicting rebleeding. GBS was better for predicting need for blood transfusions or interventions. Thus, there was no single scoring system which was superior to others in answering all the questions.

In another study published in this issue of the Journal, Rout et al. [15] prospectively studied a large cohort (1011 UGIB patients) with the aim of finding out whether the scoring systems perform equally well for variceal and non-variceal UGIB. They found that the scoring systems predict outcomes better for non-variceal UGIB. These findings are similar to an earlier published study from India [16]. Rout et al. found that AIMS65 was the best predictor of mortality, probably because it does include albumin levels and INR, both measures of liver failure.

The scoring systems for UGIB were primarily developed and tested in cohorts with predominant non-variceal UGIB, and Rout et al. as well as some previous studies show us that these scores may not perform as well for patients with variceal UGIB [17]. Rout et al. also did not find a single scoring system, which gives all the requisite prognostic information.

Both the studies published in this issue validate the utility of UGIB scores in Indian patients, with the caution from Rout et al. that they may not perform as well in the variceal UGIB cohort. There are large prospective studies similar to those of Chandnani et al. and Rout et al. with more or less similar published results [11-13]. There are several unanswered questions. Are UGIB scoring systems routinely used in India? If not, what is preventing their regular use in emergency departments? Do we need a separate score for variceal UGIB, despite having a plethora of already available scoring systems? It is obvious in today's personalized medicine environment that there is no one fit for all patients. An elderly patient with low scores might still need admission for observation, and possible endoscopy. But it is imperative upon our societies to exhort the gastroenterologists to utilize these scoring systems, to bring uniformity in care, and better standardization of data.

\section{Compliance with ethical standards}

Conflict of interest VD, and RS declare that they have no conflict of interest.

Disclaimer The authors are solely responsible for the data and the content of the paper. In no way, the Honorary Editor-in-Chief, Editorial Board Members, or the printer/publishers are responsible for the results/ findings and content of this article.

\section{References}

1. Liang PS, Saltzman JR. A national survey on the initial management of upper gastrointestinal bleeding. J Clin Gastroenterol. 2014;48:e93-8.

2. Blatchford O, Murray WR, Blatchford M. A risk score to predict need for treatment for upper gastrointestinal hemorrhage. Lancet. 2000;356:1318-21.

3. Saltzman JR, Tabak YP, Hyett BH, Sun X, Travis AC, Johannes RS. A simple risk score accurately predicts in-hospital mortality, length of stay, and cost in upper GI bleeding. Gastrointest Endosc. 2011;74:1215-24.

4. Rockall TA, Logan RF, Devlin HB, Northfield TC. Risk assessment after acute upper gastrointestinal hemorrhage. Gut. 1996;38:316-21.

5. Contreras-Omana R, Alfaro-Reynoso JA, Cruz-Chavez CE, et al. The Progetto Nazionale Emorragia Digestiva (PNED) system vs the Rockall score as mortality predictors in patients with non-variceal upper gastrointestinal bleeding: a multicenter prospective study. Rev Gastroenterol Mex. 2017;82:123-8.

6. Tammaro L, Buda A, Di Paolo MC, et al. A simplified clinical risk score predicts the need for early endoscopy in non-variceal upper gastrointestinal bleeding. Digest Liver Dis. 2014;46:783-7.

7. Hay JA, Lyubashevsky E, Elashoff J, Maldonado L, Weingarten SR, Ellrodt AG. Upper gastrointestinal hemorrhage clinical guideline: determining the optimal hospital length of stay. Am J Med. 1996;100: 313-22.

8. Saeed ZA, Winchester CB, Michaletz PA, Woods KL, Graham D. A scoring system to predict rebleeding after endoscopic therapy of nonvariceal upper gastrointestinal hemorrhage, with a comparison of heat probe and ethanol injection. Am J Gastroenterol. 1993;88:1842-9.

9. Forrest JA, Finlayson ND, Shearman DJ. Endoscopy in gastrointestinal bleeding. Lancet. 1974;2:394-7.

10. Kumar NL, Claggett BL, Cohen AJ, Nayor J, Saltzman JR. Association between an increase in blood urea nitrogen at 24 hours and worse outcome in acute nonvariceal upper GI bleeding. Gastrointest Endosc. 2017;86:1022-7.

11. Rockall TA, Logan RF, Devlin HB, Northfield TC. Selection of patients for early discharge or outpatient care after acute upper gastrointestinal haemorrhage. National Audit of Acute Upper Gastrointestinal Haemorrhage. Lancet. 1996;347: 1138-40.

12. Abougergi MS, Charpentier JP, Bethea E, et al. A prospective multicentre study of the AIMS65 score compared with the Glasgow Blatchford score in predicting upper gastrointestinal haemorrhage outcomes. J Clin Gastroenterol. 2016;50:464-9.

13. Robertson M, Majumdar A, Boyapati R, et al. Risk stratification in acute upper GI bleeding. Comparison of AIMS65 score with the Glasgow-Blatchford and Rockall scoring systems. Gastrointest Endosc. 2016;63:1151-60.

14. Chandnani S, Rathi P, Sonthalia N, et al. Comparison of risk scores in upper GI bleed in western India: a prospective analysis. Indian J Gastroenterol 2019;38; https://doi.org/10.1007/s12664-019-00951-w. 
15. Rout G, Sharma S, Gunjan D, Kedia S, Naik B, Shalimar. Comparison of various prognostic scores in variceal and non-variceal upper gastrointestinal bleeding: a prospective cohort study. Indian J Gastroenterol 2019;38; https://doi.org/10.1007/s12664-018-0928-8.

16. Sharma S, Jeyaraman P, Rana SS, et al. Utility of clinical and complete Rockall score in Indian patients with upper gastrointestinal bleeding. Trop Gastroenterol. 2016;37:276-82.
17. Thanapirom K, Ridtitid W, Rerknimitr R, et al. Prospective comparison of three risk scoring systems in non-variceal and variceal upper gastrointestinal bleeding. J Gastroenterol Hepatol. 2016;31: $761-7$.

Publisher's note Springer Nature remains neutral with regard to jurisdictional claims in published maps and institutional affiliations. 